\title{
Oleanolic Acid Attenuates Morphine Withdrawal Symptoms in Rodents: Association with Regulation of Dopamine Function
}

\author{
Zhiqi Shi $\mathbb{D}^{1,2}$ \\ Shugang $\operatorname{Pan}^{3,4}$ \\ Luolin Wang ${ }^{5}$ \\ Sha $\mathrm{Li}^{2}$
}

'School of Pharmacy, Changzhou Institute of Industry and Technology, Changzhou, Jiangsu, People's Republic of China; ${ }^{2}$ Longsha Medical Research Institute, Wuxi Hospital of Traditional Chinese Medicine, Wuxi, Jiangsu, People's Republic of China; ${ }^{3}$ School of Pharmacy, Changzhou Institute of Technology, Changzhou, 213022, People's Republic of China; ${ }^{4}$ Key Laboratory for Soft Chemistry and Functional Materials of Ministry Education, Nanjing University of Science and Technology, Nanjing, People's Republic of China; ${ }^{5}$ Department of Pharmacy, Guangdong Provincial Institute of Traditional Chinese Medicine, Guangzhou, People's Republic of China

Correspondence: Zhiqi Shi

School of Pharmacy, Changzhou Institute of Industry and Technology, No. 28\#,

Mingxin Road, Changzhou, Jiangsu

Province, 213164, People's Republic of

China

Tel +86 519-86335II8

Emailshi_mars@foxmail.com

Sha Li

Longsha Medical Research Institute, Wuxi Hospital of Traditional Chinese Medicine, No. 8\#, Zhongnan Road, Wuxi, Jiangsu Province, 21407I, People's Republic of China

Tel +86 510-88859999

Email s10426@foxmail.com
Introduction: Oleanolic acid (OA) has been shown to be useful for the treatment of mental disorders.

Methods: In this study, we investigated the effects of OA in animal models of spontaneous withdrawal and naloxone-precipitated withdrawal and evaluated the effects of OA on the acquisition, extinction, and reinstatement of morphine-induced conditioned place preference (CPP).

Results: OA significantly improved symptoms of withdrawal, and significantly reduced the acquisition and reinstatement of morphine-induced conditioned place preference. Moreover, OA significantly reduced the serum content of 5-hydroxy tryptamine (5-HT) and dopamine (DA) in a dose-dependent manner, and reduced norepinephrine (NE) and 5-HT content in the frontal cortex (PFC), while significantly increasing endorphin content in rats. OA also significantly reduced serum DA content in mice.

Conclusion: These results indicate that OA can improve the withdrawal symptoms of rats and mice by regulating the DA system and suggest that OA may be useful in treatment of morphine addiction.

Keywords: OA, withdrawal, morphine-induced, rats, mice

\section{Introduction}

Drug addiction, especially opioid addiction, is a major problem worldwide and has become a major public hazard. ${ }^{1,2}$ Repeated use of drugs in addicts prompts them to relapse into drug seeking following detoxification. Addictive drugs include narcotics and psychotropic drugs that promote dependency. ${ }^{3}$ These drugs including opioids can effectively treat pain but are highly addictive. If a dependent person suddenly stops taking drugs, he/she will exhibit predictable and measurable physical signs which is known as withdrawal syndrome. ${ }^{4}$

Stopping the behavioral and psychological consequences on drug addiction is central to our work. ${ }^{5}$ Drug detoxification uses the concepts of "replacement" and "blocking". 6 "Replacement" involves replacement with a "legal, low addictive drug", such as methadone instead of heroin, and "blocking" using opioid antagonists that can inhibit the euphoric effect of opioids and reduce the positive strengthening effect of drugs. Nonetheless, treatment compliance for both of these therapies is poor. Both methods have rapid onset of effects, but they have the disadvantages of poor safety, high relapse rate, addictive liability, and unwanted 
side effects. For example, the relapse rate after successful detoxification with methadone replacement therapy is as high as $93.4 \%$, which may lead to life-long dependence. ${ }^{7}$

There are at least four known interacting neural circuits in the brain related to the drug addiction process. ${ }^{8}$ The first circuit is located in the nucleus accumbens (NAc) and the ventral globus pallidus, which regulate the reward process; the second circuit is located in the orbitofrontal cortex and the inferior cingulate cortex, which are responsible for regulating motivation and emotion; the third circuit involves the amygdala and hippocampus, which produce memorize and support conditional learning; the last circuit is located in the PFC and the anterior cingulate gyrus, which master advanced cognitive control and executive ability. ${ }^{9}$

The four neural circuits receive their own direct or indirect neural projections, which play an important role in regulating craving and relapse for drugs. ${ }^{10}$ Among them, the DA nervous system is the material basis of drug rewards. This system originates from the ventral dorsal tegmental area (VTA), and mainly projects to the NAc, amygdala, PFC, and other brain areas. Addictive drugs can quickly cause the activation of DA neurons in the VTA of the midbrain, and increase the level of DA in the NAc to produce euphoria. ${ }^{11}$

Furthermore, it is known that the DA system is involved in mediating the psychologically dependent effects of morphine, and the glutamatergic projection of the reward pathway from the PFC and amygdala to the midbrain plays a role in regulating DA neuron. ${ }^{12}$ Addictive drugs change neuronal cellular proteins in the central nervous system (CNS), including G protein coupled receptors and protein kinases, which can result in addiction. ${ }^{13}$ Moreover, interactions between the DA and glutamate systems are essential for the development of the rewarding effects of opiates. In addition, the release of NE, DA, $\gamma$-aminobutyric acid, glutamate, and other substances are also involved in the opioid addiction process, which is accompanied by neuronal changes at the molecular level. ${ }^{14}$ Thus, drug addiction is inseparable from the DA system.

In our previous study, we found that traditional Chinese herbal medicines including oleanolic acid (OA) can reduce drug addiction or even promote detoxification. ${ }^{15} \mathrm{OA}$ is widely found in food, medicinal herbs, and in more than 190 plants of about 60 families. OA is mainly present in the form of root and rhizome saponins in plants from families such as Araliaceae, Cucurbitaceae, Asclepiaceae, and Ranunculaceae, while it is found in leaves and fruits from plants in Lepidaceae, Gentiana, Rubiaceae, Amaranthaceae, and Ranunculaceae. ${ }^{16} \mathrm{OA}$ is a pentacyclic triterpenoid white crystalline powder that is odorless and tasteless. As early as 1908, FB Powers isolated OA for the first time from the leaves of the mandarin plant Olea europaea L., and in 1946, Ruzicka determined its structure. ${ }^{17}$ OA has multiple pharmacological functions such as being an antioxidant, antiinflammatory, hepato-protective, and enhances the body's immune defense systems. ${ }^{18-21}$ Although there are few studies demonstrating the effects of OA on mental status, it has been reported that sub-chronic OA treatment showed antidepressant-like effects due to increased serotonin, 5-hydroxyindoleacetic acid/5-HT ratio, and NE levels in the PFC, suggesting that $O A$ may affect the catecholamine metabolism. ${ }^{22}$

In this study, we investigated the effects of $\mathrm{OA}$ in animal models of spontaneous withdrawal and naloxoneprecipitated withdrawal, and evaluated the effects of OA on the acquisition, extinction, and reinstatement of morphine-induced CPP.

\section{Materials and Methods}

Chemicals

OA (3ß-hydroxyolean-12-en-28-oic acid) was purchased from Acetar Bio-tech Inc. (Shanxi, China). Clonidine hydrochloride tablets for treating addiction were purchased as a positive control drug from Changzhou Pharmaceutical Factory Co., Ltd. (Jiangsu, China).

The Jitai tablet consisting of 15 herbs was first prescribed by JitaiYang, a famous doctor in the Qing Dynasty and more recently has been approved by the China Food and Drug Administration for use in the clinical treatment of opiate addiction. ${ }^{23}$ Jitai tablets were purchased as a positive control drug of Traditional Chinese Medicine from Wuhan Ezhong Pharmaceutical Co., Ltd. (Hubei, China). ${ }^{24-26}$

OA, clonidine hydrochloride tablets, and Jitai tablets were all prepared as warm water suspensions. Morphine hydrochloride solution for injection was obtained from Shenyang No.1 Pharmaceutical Co., Ltd. of Northeast Pharmaceutical Group (Liaoning, China). Naloxone hydrochloride solution for injection was obtained from Beijing Kain Technology Co., Ltd. (Beijing, China). ELISA kits for DA, 5-HT, NE, and endorphin were all purchased from Shanghai Xitang Biotechnology Co., Ltd.

\section{Animals}

160 male SD rats (weighing 180-220 g), and 70 male NIH mice (weighing 18-22 g) were obtained from Guangdong 
Medical Laboratory Animal Center and were housed under $12 \mathrm{~h}: 12 \mathrm{~h}$ light-dark cycle at a constant temperature of 22 $\pm 2{ }^{\circ} \mathrm{C}$ and $40 \%-50 \%$ humidity. All laboratory animals had ad libitum access to water and food. All treatments were carried out according to the Guangdong Institute of Traditional Chinese Medicine, Ethical Committee Acts.

Three classic models were applied to study the effect of OA on drug addiction, including spontaneous withdrawal test in rats, precipitated withdrawal test in rats and mice, and CPP study in mice. The specific experimental plan is as follows.

\section{The Morphine-Dependent Rat Model (Spontaneous Withdrawal)}

The morphine-dependent rat model was replicated from previous studies using the dose-escalation method. ${ }^{27,28}$ Seventy rats were randomly divided into 7 groups (I-VII) as shown in Figure 1. Group I was a normal control group where normal saline was injected subcutaneously (s.c.). Groups (II-VII) were all injected with morphine for 28 days. Each group was injected continuously for 28 days, and then the drug was stopped with withdrawal occurring spontaneously.

The morphine-dependent rat model (spontaneous withdrawal): OA Treatment.

On the 29th day, morphine was stopped (spontaneous withdrawal), and each group was treated as shown in Figure 1. Each group was administered drug for 5 consecutive days. Two hours after treatment on the 1st day (d1), 3rd day (d3), and 5th day (d5), rats were scored for withdrawal responses, and weights were recorded.

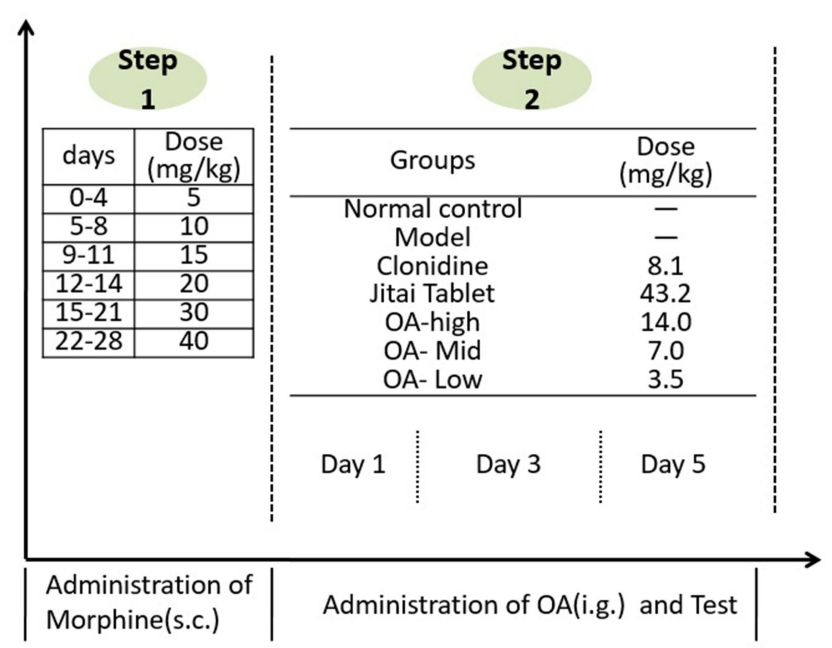

Figure I The morphine-dependent rat model (Spontaneous withdrawal) and treatment of OA.
Within a 30-minute period, rats were scored for wet dog shaking, stereotyped movements, standing, and jumping. Rats were scored every 5 minutes to assess ptosis, irritation, tooth tremors and chewing, erect hair, abnormal posture, and shortness of breath. Symptoms of diarrhea, tearing, salivation, and runny nose were additionally scored once within 30 minutes.

Countable symptoms included wet dog shaking for 1 minute/scoring session; stereotyped movements for 0.5 minute/session; standing upright for 1 minute/session; jumping for 2 minutes/session.

Uncountable symptoms included abnormal posture (2 points); vertical hair (1 point); tooth tremor (2 points); shortness of breath ( 3 points); ptosis ( 2 points); irritability (2 points).

Other symptoms included diarrhea-soft stool (4 points), irregular ( 8 points) or absent diarrhea ( 0 points); tearingmild ( 1 point), obvious ( 2 points), or absent tearing ( 0 points); runny nose-mild (1 point), obvious ( 2 points), or absent runny nose ( 0 points); salivation-mild ( 2 points), obvious ( 3 points), or absent salivation ( 0 points).

The sum of the above was the total score for the withdrawal reaction.

Determination of 5-HT and DA in the blood of morphine-dependent rats.

After d5 observations, blood draws were quickly taken, centrifuged by $3000 \mathrm{r} / \mathrm{min}$ at $4^{\circ} \mathrm{C}$ for $10 \mathrm{~min}$, and the serum was taken for determination according to the 5-HT and DA kit instructions.

\section{The Morphine-Dependent Rat Model (Naloxone-Precipitated Withdrawal)}

Ninety rats were randomly divided into two groups: 10 rats in the control group and 80 rats in the morphine-dependent model group. Rats in the model group were treated as described above for groups II-IX (Figure 2). Injections of morphine hydrochloride were given every 12 hours (8:00 am, 8:00 pm) at doses gradually increasing from 5 to $80 \mathrm{mg} /$ $\mathrm{kg}$ (s.c.) and continued until the 9th day. The injection volume was $0.2 \mathrm{~mL} / 100 \mathrm{~g}$. Rats in the control group were given normal saline. On the 10th day, study rats were administered naloxone $(4.0 \mathrm{mg} / \mathrm{kg}$, intraperitoneally), and scored to measure the withdrawal response. Rats in the control group were injected with normal saline. ${ }^{29,30}$

Withdrawal symptoms score of morphine-dependent rats.

According to the improved Yanagi Koji score standard, rats were scored for the following withdrawal symptoms: abnormal posture ( 2 points); high irritability: touch ( 1 point), 


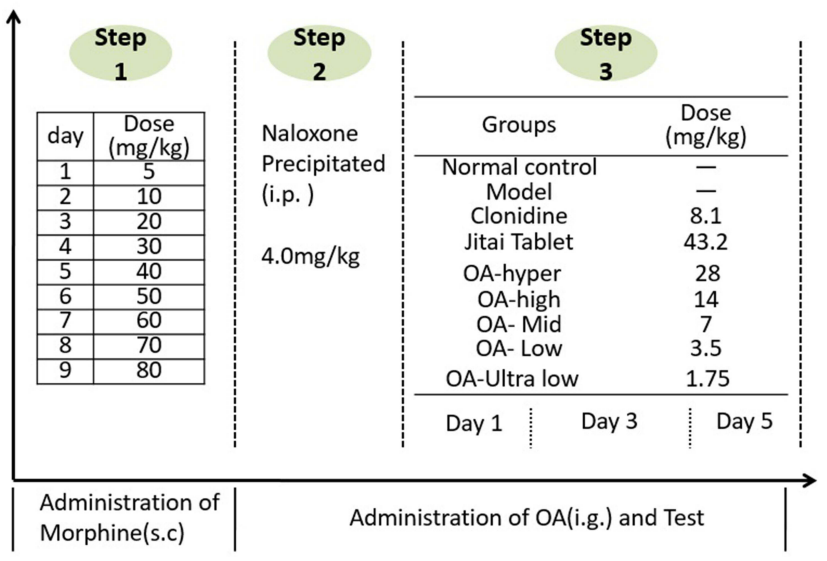

Figure 2 The morphine-dependent rat model (Naloxone-precipitated withdrawal) and treatment of $\mathrm{OA}$.

close to each other (2 points); intentional tremor: intermittent ( 1 point), continuous ( 2 points); Biting: intermittent $(0.5$ points), continuous (1 point); irritability: mild (0.5 points), obvious (1 point); tears (4 Points); diarrhea: soft stools (4 points), no shape (8 points); drooling: mild (1 point), obvious ( 2 points); weight loss: $2 \%$ (0 points), 2-4\% (5 points), 4-6\% (10 points), 6-8\% (15 points). Each withdrawal symptom score was the sum of all symptom scores. ${ }^{31}$

The morphine-dependent rat model (Naloxoneprecipitated withdrawal): OA treatment.

The rats in the morphine-dependent model group were divided and treated as shown in Figure 2. Each group was administered drug continuously for 5 days. Naloxone (4.0 $\mathrm{mg} / \mathrm{kg}$, intraperitoneally) was administered after 2 hours of treatment on the 1 st (d1), 3rd (d3), and 5th day (d3), and the withdrawal response of rats was observed within $30 \mathrm{~min}$ and body weight was recorded.

Determination of NE, 5-HT and endorphin in the PFC of rats.

The PFC was dissected, weighed, and sodium chloride solution $(0.1 \mathrm{~mol} / \mathrm{L})$ was added followed by homogenization to form a $10 \%$ homogenate. The homogenate was then centrifuged at $15000 \mathrm{r} / \mathrm{min}$ at $4^{\circ} \mathrm{C}$ for 30 minutes, and the supernatant was taken to measure the levels of NE, 5-HT, and endorphin by ELISA.

\section{The Morphine-Dependent Mouse Model (Naloxone-Precipitated): OA Treatment}

70 mice were randomly divided into 7 groups according to their body weight. Groups included a normal control group, model control group, clonidine group, Jitai tablet group, and the OA high, medium, and low-dose groups as described above.

The normal control group was injected with an equal volume of $0.9 \%$ sodium chloride for 6 consecutive days. Mice in the other groups were injected with morphine as shown in Figure 3. At the same time, OA were administered as described above. 45 minutes after the last administration, mice were injected with naloxone $(6 \mathrm{mg} / \mathrm{kg}$, intraperitoneally). The number of jumping reactions within 30 minutes was measured, and the changes in body weight $1 \mathrm{~h}$ before and after the jumping reaction were compared. ${ }^{32,33}$ Weight loss $=$ weight of mice before naloxone injection-weight of mice after jumping response.

\section{Conditioned Place Preference (CPP) Analysis}

The light and dark box device for mice was made by the Institute of Materia Medica, Chinese Academy of Medical Sciences. The experimental device consisted of two connected light and dark cells. 1/2 was a light room, 1/2 was a dark room, and there was a partition in the middle to separate the light and dark rooms. The mice could move freely between the light and dark rooms. The inside and outside walls of the dark box were black with a soft blanket floor, and the inside and outside walls of the bright box were white with as mooth floor. The whole experiment box had both visual and tactile cues. When the morphine-dependent studies had been completed, all of the mice were placed in the CPP apparatus for a period of 900s daily with the guillotine doors open. This schedule was repeated for 7 days to eliminate morphine dependency. Utilizing this system, extinction of place preference is acquired when the difference between the time spent in the white compartment in the extinction phase and pre-conditioning phase is not significant.

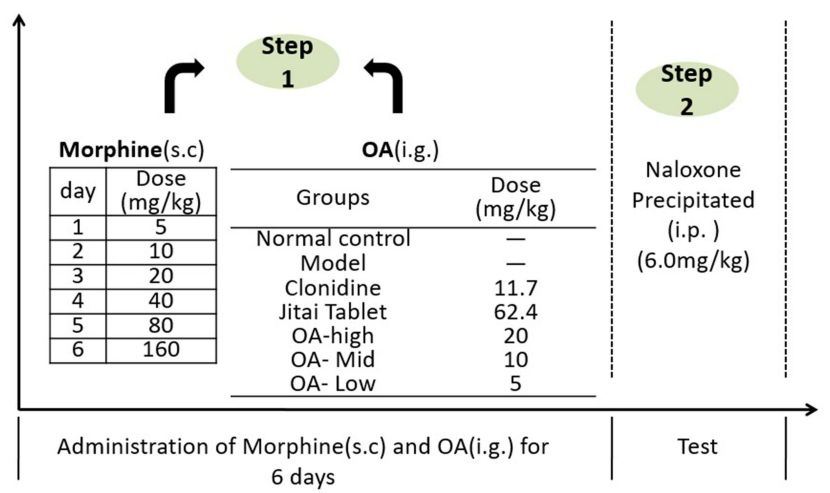

Figure 3 The morphine-dependent mouse model (Naloxone-precipitated withdrawal) and treatment of $O A$. 


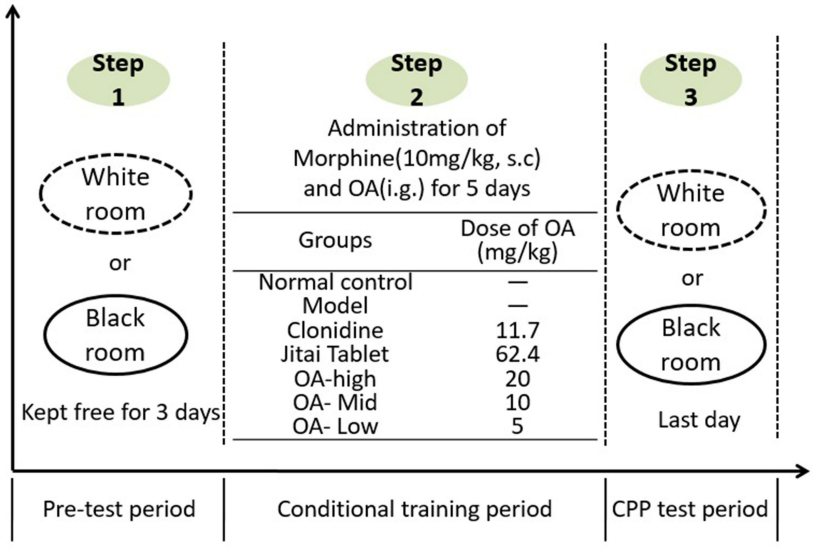

Figure 4 The experimental steps of CPP.

Establishment of the CPP model was divided into three stages: a pre-test period (natural preference test stage), conditional training period, and CPP test period (Figure 4). ${ }^{34,35}$

(1) Pre-test period: the mice were kept adaptively in the animal laboratory for 2 days. On the third day, the mice were placed in the middle of the light and dark box device and the residence time of mice in each box was observed one by one for 15 minutes. The observation process was conducted under sound proof conditions. Throughout the experiments, the mice were offered food and water ad libitum. Mice with a significant preference for one side of the box were eliminated to exclude the effect of unconditional positional preference on the results. Because the results showed that almost all mice preferred the black box, the white box was regarded as the non-preferred side.

(2) Conditional training period: mice that met the experimental conditions were randomly divided into 7 groups as described previously. In addition to the normal control group, mice in each group were injected with $10 \mathrm{mg} / \mathrm{kg}$ morphine hydrochloride and saline every day (s.c.), all of which were injected for 6 hours at intervals of 5 days. After morphine injection, they were placed in the non-preferred side of the white box. By contrast, mice which were injected with saline were placed in the preferred side of the black box. Before morphine injection, mice in each group were administered OA for 30 minutes, and the normal control group and model control group were administered intragastrically with an equal volume of distilled water.

(3) CPP test period: 24 hours after the last drug injection, the CPP test was performed. The test process was the same as the observation process in the pre-test phase.

Extinction of place preference
After the post-conditioning phase, some groups of mice were also placed in the CPP apparatus for a period of 900 s daily with the guillotine doors open. The schedule was repeated for 7 days to eliminate morphine dependency. ${ }^{34}$

Determination of DA in the blood of morphinedependent mice

After the CPP test, blood was quickly drawn into $4 \%$ EDTA-2Na, centrifuged at $3000 \mathrm{r} / \mathrm{min}$ at $4^{\circ} \mathrm{C}$ for $10 \mathrm{~min}$, and the serum was taken for ELISA analysis of DA content.

\section{Statistical Analysis}

All measurement data are expressed as mean \pm SEM. Oneway analysis of variance (ANOVA) was used for data analysis in SPSS 20.0, with $\mathrm{p}<0.05$ considered significant, followed by Tukey's post-hoc tests.

\section{Results}

\section{Therapeutic Effect of OA on Spontaneous Withdrawal Symptoms in Morphine Dependent Rats}

Figure 5 displays a comparison of spontaneous withdrawal scores on d1 $\left[\mathrm{F}_{(1,18)}=3316.71, \quad P<0.01\right], \quad \mathrm{d} 3\left[\mathrm{~F}_{(1,18)}\right.$ $=3011.32, \quad P<0.01], \quad$ and $\mathrm{d} 5\left[\mathrm{~F}_{(1,18)}=2829.11, \quad P<0.01\right]$ which were all significantly increased compared to the control group. Compared to the model control group, the spontaneous withdrawal scores at $\mathrm{d} 1, \mathrm{~d} 3$, and $\mathrm{d} 5$ were significantly reduced in the OA-treated groups. Compared with the clonidine group, spontaneous withdrawal scores of the middle-dose group of $\mathrm{OA}$ on $\mathrm{d} 3\left[\mathrm{~F}_{(1,18)}\right.$ $=21.32, P<0.01]$ and $\mathrm{d} 5\left[\mathrm{~F}_{(1,18)}=35.03, P<0.01\right]$ were significantly reduced. Compared with the Jitai group, spontaneous withdrawal scores of the middle-dose group of OA

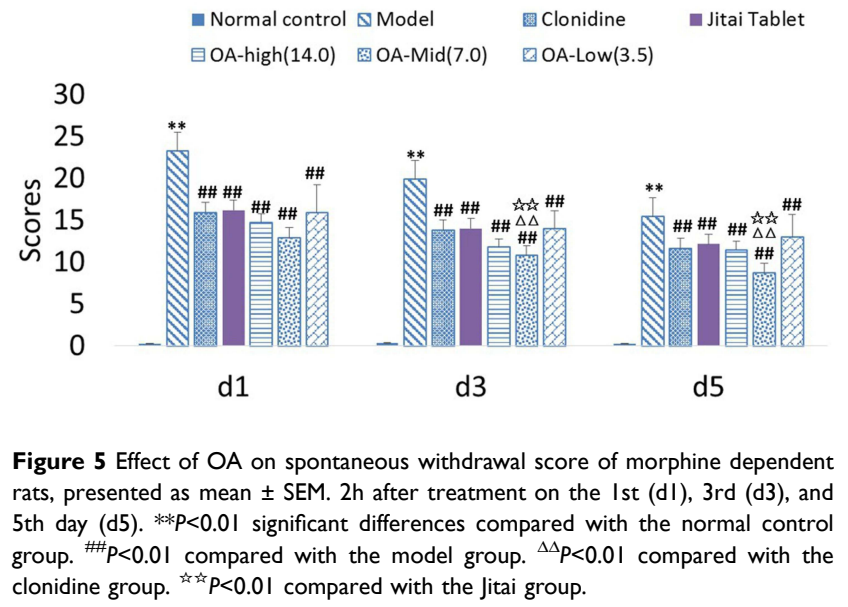




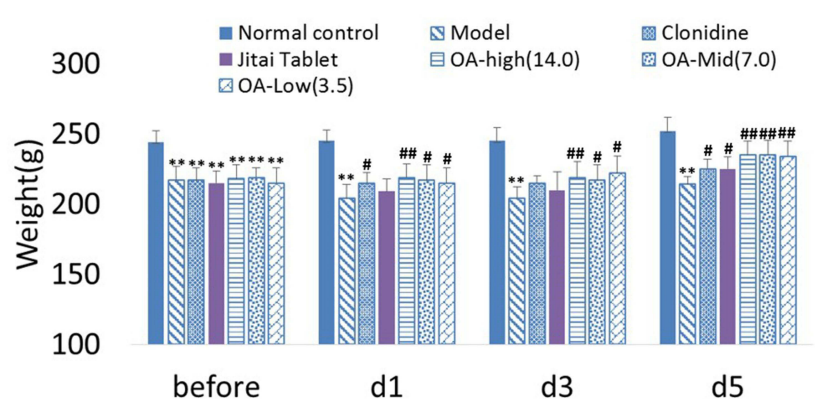

Figure 6 Effect of OA on the weight of spontaneous withdrawal morphinedependent rats, presented as mean \pm SEM. $2 \mathrm{~h}$ after treatment on the Ist $(\mathrm{dI})$, 3rd (d3), and 5thday (d5). "Before" means before administration of OA. **P<0.01 significant differences compared with the normal control group. ${ }^{\#} P<0.05,{ }^{\#} P<0.01$ compared with the model group.

on $\mathrm{d} 3 \quad\left[\mathrm{~F}_{(1,18)}=24.30, \quad P<0.01\right]$ and $\mathrm{d} 5\left[\mathrm{~F}_{(1,18)}=40.12\right.$, $P<0.01]$ was also significantly reduced.

Body weight of morphine-dependent rats before administration of $\mathrm{OA}$ was significantly $\left[\mathrm{F}_{(1,68)}=84.74, P<0.01\right]$ reduced compared to the normal control group (Figure 6), but the weight of morphine-dependent rats was the same [maximum $\mathrm{F}_{(1,18)}=0.86$, NS]. Compared with the normal control group, body weights of the $\mathrm{d} 1\left[\mathrm{~F}_{(1,18)}=27.74\right.$, $\mathrm{P}<0.01], \mathrm{d} 3\left[\mathrm{~F}_{(1,18)}=24.70, P<0.01\right]$, and $\mathrm{d} 5\left[\mathrm{~F}_{(1,18)}=22.69\right.$, $P<0.01]$ model control groups were all significantly reduced. Compared to the model control group, the weight on $\mathrm{d} 1\left[\mathrm{~F}_{(1,18)}=15.54, P<0.01\right], \mathrm{d} 3\left[\mathrm{~F}_{(1,18)}=17.43, P<0.01\right]$, and $\mathrm{d} 5\left[\mathrm{~F}_{(1,18)}=18.46, P<0.01\right]$ all increased significantly in the high-dose groups. The weight on $\mathrm{d} 1\left[\mathrm{Mid}: \mathrm{F}_{(1,18)}=4.95\right.$, $P<0.05$; Low: $\left.\mathrm{F}_{(1,18)}=4.82, \quad P<0.05\right] \quad$ and $\mathrm{d} 3\left[\mathrm{Mid}: \mathrm{F}_{(1,18)}\right.$ $=4.12, P<0.05$; Low: $\left.\mathrm{F}_{(1,18)}=6.01, \mathrm{P}<0.05\right]$ increased significantly in both the mid and low-dose groups. The weight on d5 increased significantly in both the mid and low-dose groups. Compared with the clonidine group, body weights in the high, middle, and low dose OA groups were not significantly different $\quad\left[\right.$ High: $\mathrm{F}_{(1,18)}=3.72, \quad P>0.05$; Mid: $\mathrm{F}_{(1,18)}=2.89, \quad P>0.05 ;$ Low: $\left.\mathrm{F}_{(1,18)}=2.15, \quad P>0.05\right]$. Compared with the Jitai group, the weights of rats in the high, middle, and low OA dose groups on $\mathrm{d} 1, \mathrm{~d} 3$, and $\mathrm{d} 5$ all increased, but not significantly (Figure 6, $P>0.05$ ).

Figure 7 compares serum 5-HT and DA content. Compared with the normal control group, the serum levels of 5-HT $\left[\mathrm{F}_{(1,18)}=3893.47, P<0.01\right]$ and $\mathrm{DA}\left[\mathrm{F}_{(1,18)}=\right.$ 3997.36, $P<0.01]$ in the model control group increased significantly. However, compared with the model control group, the serum 5-HT and DA levels of rats in the OA high [5-HT: $\left.\mathrm{F}_{(1,18)}=904.51, P<0.01 ; \mathrm{DA}: \mathrm{F}_{(1,18)}=948.11, P<0.01\right]$, medium [5-HT: $\quad \mathrm{F}_{(1,18)}=927.87, \quad P<0.01 ; \quad \mathrm{DA}: \mathrm{F}_{(1,18)}$

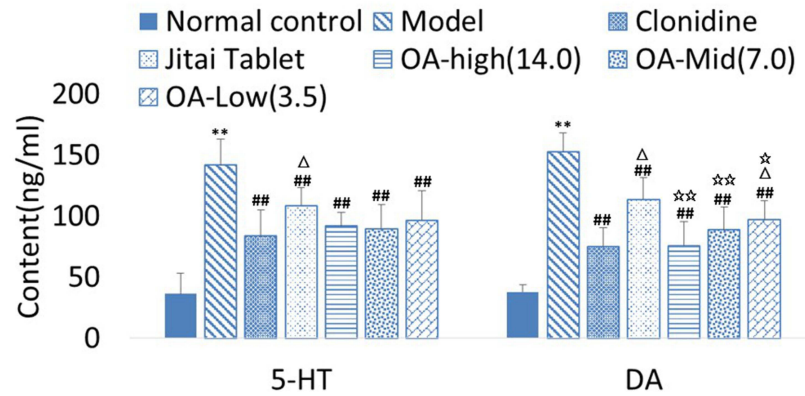

Figure 7 Effect of OA on serum 5-HT and DA levels in morphine-dependent rats with spontaneous withdrawal, presented as mean \pm SEM. $* * P<0.01$ significant differences compared with the normal control group. ${ }^{\#} P<0.01$ compared with the model group. ${ }^{\Delta} P<0.05$ compared with the clonidine group. $P<0.05$, मे $P<0.01$ compared with the Jitai group.

$=902.69, P<0.01]$ and low $\left[5-\mathrm{HT}: \mathrm{F}_{(1,18)}=885.14, P<0.01\right.$; $\left.\mathrm{DA}: \mathrm{F}_{(1,18)}=897.45, P<0.01\right]$ dose groups were all significantly reduced. Compared with the clonidine group, there was no significant differences in serum 5-HT or DA levels in any $\mathrm{OA}$ group (Figure 7, $P>0.05$ ). Compared with the Jitai group, the serum DA content in the OA high $\left[\mathrm{F}_{(1,18)}\right.$ $=12.16, P<0.01]$, medium $\left[\mathrm{F}_{(1,18)}=9.45, P<0.01\right]$ and lowdose groups $\left[\mathrm{Mid}: \mathrm{F}_{(1,18)}=4.92, P<0.05\right]$ were significantly reduced, while the 5-HT content was slightly reduced in all OA groups [maximum $\left.\mathrm{F}_{(1,18)}=3.71, \mathrm{NS}\right]$.

\section{Therapeutic and Dose-Effect Relationship of OA on Withdrawal Symptoms in Morphine Dependent Rats (Naloxone-Precipitated)}

As shown in Figure 8, withdrawal scores before OA administration were significantly increased compared with the normal control group $\left[\mathrm{F}_{(1,18)}=1389.92, P<0.01\right]$.

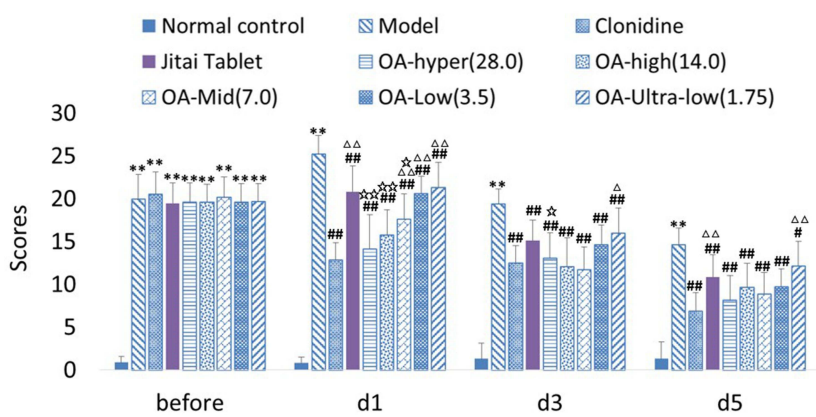

Figure 8 Effect of OA on withdrawal score of morphine dependent rats, presented as mean \pm SEM. $2 \mathrm{~h}$ after treatment on the Ist (dI), 3rd (d3), and 5th day (d5). "Before" means before administration of $O A$. $* * P<0.01$ significant differences compared with the normal control group. ${ }^{\#} P<0.05,{ }^{\#} P<0.01$ compared with the model group. ${ }^{\Delta} P<0.05,{ }^{\Delta \Delta} P<0.01$ compared with the clonidine group. ${ }^{\circ} P<0.05$, ${ }^{2}{ }^{2} P<0.01$ compared with thejitai group. 
There was also no significant difference of withdrawal scores before administration compared with the model control group [maximum $\mathrm{F}_{(1,18)}=0.84, \mathrm{NS}$ ].

After OA administrated as shown in Figure 8, on d1, $\mathrm{d} 3$, and $\mathrm{d} 5$, model control groups still have significantly higher withdrawal scores compared to the normal control group $\left[\mathrm{d} 1: \mathrm{F}_{(1,18)}=1281.28, \quad P<0.01 ; \quad \mathrm{d} 3: \mathrm{F}_{(1,18)}=912.47\right.$, $\left.P<0.01 ; \mathrm{d} 5: \mathrm{F}_{(1,18)}=748.59, P<0.01\right]$. The withdrawal scores of the OA groups (Hyper-28.0; High-14.0; Mid:7.0; Low-3.5) were all significantly reduced compared to the model control group [minimum $\mathrm{F}_{(1,18)}$ $=48.07, P<0.01]$, and the withdrawal scores of the $\mathrm{OA}$ (Ultra low-1.75) groups were significantly reduced on $\mathrm{d} 1$ $\left[\mathrm{F}_{(1,18)}=58.96, P<0.01\right], \mathrm{d} 3 \quad\left[\mathrm{~F}_{(1,18)}=48.48, P<0.01\right]$, and $\mathrm{d} 5\left[\mathrm{~F}_{(1,18)}=5.32, P<0.01\right]$ stages.

Compared with the clonidine group, the withdrawal scores in all OA groups on $\mathrm{d} 1$ were all significantly increased [minimum $\left.\mathrm{F}_{(1,18)}=12.09, P<0.01\right]$. The withdrawal scores of the ultra-low OA group were significantly increased on $\mathrm{d} 3$ and $\mathrm{d} 5\left[\mathrm{~d} 3: \mathrm{F}_{(1,18)}=5.12, P<0.05 ; \mathrm{d} 5: \mathrm{F}_{(1,18)}=15.46, P<0.01\right]$, but there was no significant difference in either hyper or high dose groups [maximum $\mathrm{F}_{(1,18)}=2.62, \mathrm{NS}$ ].

Compared with the Jitai group, the withdrawal scores of the hyper (28.0) OA groups were significantly decreased on $\mathrm{d} 1$ and $\mathrm{d} 3\left[\mathrm{~d} 1: \mathrm{F}_{(1,18)}=23.30, P<0.01 ; \mathrm{d} 3: \mathrm{F}_{(1,}, 18\right)=6.90$, $P<0.05]$. The withdrawal scores of the high (14.0) OA groups were significantly decreased and $1\left[\mathrm{~F}_{(1,18)}=5.91, P<0.05\right]$.

Compared to controls, the NE and 5-HT content was increased significantly in the model control group (Table 1) [NE: $\left.\mathrm{F}_{(1,18)}=386.24, P<0.01 ; 5-\mathrm{HT}: \mathrm{F}_{(1,18)}=261.25, P<0.01\right]$, but the endorphin content was significantly reduced in all

Table I The Effect of OA on the Content of NE, 5-HT and Endorphin in the Frontal Cortex of Morphine-Dependent Rats

\begin{tabular}{|c|c|c|c|}
\hline \multirow[t]{2}{*}{ Groups } & NE & 5-HT & Endorphin \\
\hline & ng/mg & ng/mg & ng/mg \\
\hline Normal control & $0.46 \pm 0.04$ & $0.42 \pm 0.08$ & $0.13 \pm 0.01$ \\
\hline Model & $1.98 \pm 0.09 * *$ & $1.74 \pm 0.15^{* *}$ & $0.06 \pm 0.0 I^{* *}$ \\
\hline Clonidine & $0.73 \pm 0.09^{\# \#}$ & $0.97 \pm 0.11^{\# \#}$ & $0.11 \pm 0.01^{\# \#}$ \\
\hline Jitai Tablet & $1.29 \pm 0.10^{\# \# \Delta}$ & $1.30 \pm 0.12^{\#}$ & $0.10 \pm 0.01^{\# 1}$ \\
\hline OA-hyper(28.0) & 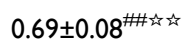 & $0.97 \pm 0.07^{\# \#}$ & $0.1 I \pm 0.0 I^{\# 1}$ \\
\hline OA-high(14.0) & $1.00 \pm 0.10^{\text {\#\#放 }}$ & $1.09 \pm 0.12^{\# \#}$ & $0.10 \pm 0.01^{\# \#}$ \\
\hline OA-Mid(7.0) & 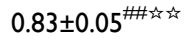 & $1.06 \pm 0.13^{\# \#}$ & $0.11 \pm 0.0 I^{\# \#}$ \\
\hline OA-Low(3.5) & $1.30 \pm 0.09^{\# \# \Delta \Delta}$ & $1.12 \pm 0.15^{\# \#}$ & $0.10 \pm 0.01^{\# \#}$ \\
\hline OA-ultralow(I.75) & $1.50 \pm 0.1 \mathrm{I}^{\# \# \Delta \Delta}$ & $1.40 \pm 0.15^{\#}$ & $0.10 \pm 0.01^{\# \#}$ \\
\hline
\end{tabular}

Notes: $* * P<0.01$ significant differences compared with normal control group. ${ }^{\#} P<0.05,{ }^{\#} P<0.01$ compared with model group. ${ }^{\Delta} P<0.05,{ }^{\Delta \Delta} P<0.01$ compared with Clonidine group. ${ }^{2} P<0.05$, ${ }^{2} P<0.01$ compared with Jitai Tablet. groups [minimumF $\left.F_{(1,18)}=36.45, P<0.01\right]$. Compared with the model control group, the content of $\mathrm{NE}$ and 5-HT in the hyper-, high-, medium-, and low-dose groups of OA was significantly lower [minimum $\mathrm{F}_{(1,18)}=17.59, P<0.01$ ], and the endorphin content was significantly higher [minimum $\left.\mathrm{F}_{(1,18)}=31.44, P<0.01\right]$. The content of NE and 5-HT in the ultra low-dose $\mathrm{OA}$ groups was significantly lower $\left[\mathrm{NE}: \mathrm{F}_{(1,18)}=42.29, P<0.01 ; 5-\mathrm{HT}: \mathrm{F}_{(1,18)}=7.36, P<0.05\right]$.

Compared with the clonidine group, the NE content in the low- and ultra-low OA dose groups was significantly higher [Low:F(1,18)=19.33, $P<0.01$; Ultra-low: $\mathrm{F}_{(1,18)}=$ $6.09, P<0.05]$, but there was no significant difference in the other groups [maximum $\left.\mathrm{F}_{(1,18)}=2.07, \mathrm{NS}\right]$. Compared with the Jitai group, the NE content was significantly reduced in the hyper- $\left[\mathrm{F}_{(1,18)}=32.18, P<0.01\right]$, high- $\left[\mathrm{F}_{(1,18)}\right.$ $=7.78, P<0.05]$ and medium- groups $[\mathrm{F}(1,18)=7.78$, $P<0.05]$, but there was no significant difference in the other groups [maximum $\mathrm{F}_{(1,18)}=3.92, \mathrm{NS}$ ].

\section{Therapeutic Effect of OA on Withdrawal Symptoms in Morphine Dependent Mice (Naloxone-Precipitated)}

Table 2 displays the number of jumping reactions and weight loss for each group. Compared to normal controls, jumping increased significantly $\left[\mathrm{F}_{(1,18)}=1621.54, P<0.01\right]$, and weight decreased significantly in model group $\left[\mathrm{F}_{(1,18)}=115.28\right.$, $P<0.01]$.

Compared with the model control group, the jumping reactions were significantly lower in the OA high-, medium-, and low-dose groups $\left[\operatorname{minimumF}_{(1,18)}=23.78\right.$, $P<0.01]$, and the weight was increased significantly [minimumF $\left._{(1,18)}=25.83, P<0.01\right]$.

Table 2 Effect of $\mathrm{OA}$ on the Withdrawal of Morphine Dependent Mice

\begin{tabular}{|c|c|c|}
\hline Groups & $\begin{array}{c}\text { Times of Jump Response } \\
\text { (Times) }\end{array}$ & Weight Loss (g) \\
\hline Normal control & $2.20 \pm 0.25$ & $0.20 \pm 0.03$ \\
\hline Model & $48.00 \pm 2.99 * *$ & $0.89 \pm 0.04 * *$ \\
\hline Clonidine & $40.00 \pm 2.50^{\#}$ & $0.53 \pm 0.04^{\# \#}$ \\
\hline Jitai Tablet & $40.00 \pm 1.94^{\#}$ & $0.57 \pm 0.03^{\# \#}$ \\
\hline OA-high(20) & 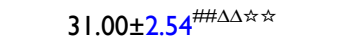 & 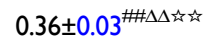 \\
\hline OA-Mid(I0) & 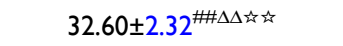 & $0.49 \pm 0.03^{\# \#}$ \\
\hline OA-Low(5) & $37.80 \pm 2.27^{\# \#}$ & $0.53 \pm 0.03^{\# \#}$ \\
\hline
\end{tabular}

Notes: $* * P<0.01$ significant differences compared with normal control group. ${ }^{\#} P<0.05,{ }^{\#} P<0.01$ compared with model group. ${ }^{\Delta \Delta} P<0.01$ compared with Clonidine group. ${ }^{2} P<0.01$ compared with Jitai Tablet. 
Compared with the clonidine group, the jumping reactions in the OA high- and medium-dose groups were significantly lower $\left[\operatorname{minimumF}_{(1,18)}=67.98, P<0.01\right]$, and the weight was increased significantly $\left[\mathrm{F}_{(1,18)}=138.22\right.$, $P<0.01]$.

Compared with the Jitai group, the number of jump reactions from mice in the $\mathrm{OA}$ high and medium-dose group were significantly lower $\left[\operatorname{minimumF}_{(1,18)}=65.78\right.$, $P<0.01]$, and the weight was also significantly increased $\left[\mathrm{F}_{(1,18)}=186.18, P<0.01\right]$.

\section{Effect of OA on the Acquisition of Morphine-Induced CPP}

As shown in Table 3, compared with the normal control group, the model control group mice spent a significantly longer time in the white box $\left[\mathrm{F}_{(1,18)}=135.76, P<0.01\right]$, and had significantly higher levels of serum DA $\left[\mathrm{F}_{(1,18)}=963.22\right.$, $P<0.01]$.

Compared with the model control group, the OA-high, medium, and-low dose groups spent significantly less time in the white box $\left[\operatorname{High:}: \mathrm{F}_{(1,18)}=79.18, \quad P<0.01 ; \quad \operatorname{Mid}: \mathrm{F}_{(1,18)}\right.$ $=81.76, P<0.01$; Low: $\left.\mathrm{F}_{(1,18)}=7.54, P<0.05\right]$, and had lower levels of serum $\mathrm{DA}\left[\right.$ minimumF $\left._{(1,18)}=104.78, P<0.01\right]$.

Compared with the clonidine group, the serum DA level of mice in the OA low-dose group was significantly higher $\left[\mathrm{F}_{(1,18)}=111.29, P<0.01\right]$, and the mice spent significantly longer in the white box $\left[\mathrm{F}_{(1,18)}\right.$ $=5.43, P<0.05]$.

Compared with the Jitai group, the OA high, medium, and low-dose groups had significantly lower serum DA levels $\left[\operatorname{minimumF}_{(1,18)}=50.77, P<0.01\right]$. TheOA-high and medium-dose groups also spent less time in the white

Table 3 Effect of OA on the Acquisition of Morphine-Induced CPP

\begin{tabular}{|c|c|c|}
\hline \multirow[t]{2}{*}{ Groups } & $\begin{array}{l}\text { Time in the White } \\
\text { Compartment }\end{array}$ & DA \\
\hline & (s) & (ng/mL) \\
\hline Normal control & $391.12 \pm 16.44$ & $67.63 \pm 3.01$ \\
\hline Model & $571.47 \pm 15.82 * *$ & $196.11 \pm 8.14^{* *}$ \\
\hline Clonidine & $449.40 \pm 22.62^{\# \#}$ & $88.85 \pm 10.27^{\# \#}$ \\
\hline Jitai Tablet & $492.02 \pm 17.06^{\#}$ & $149.69 \pm 10.40^{\# \#}$ \\
\hline OA-high(20) & $455.89 \pm 29.11^{\text {册的 }}$ & 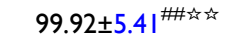 \\
\hline OA- Mid(I0) & $439.54 \pm 26.36$ \#\#文的 & 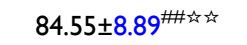 \\
\hline OA- Low(5) & $508.6 \mathrm{I} \pm 28.8 \mathrm{I}^{\# \Delta}$ & 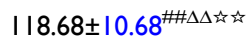 \\
\hline
\end{tabular}

Notes: $* * P<0.01$ significant differences compared with normal control group. ${ }^{\#} P<0.05,{ }^{\#} P<0.01$ compared with model group. ${ }^{\Delta} P<0.05,{ }^{\Delta \Delta} P<0.01$ compared with Clonidine group. ${ }^{2} P<0.05$, ${ }^{2} P<0.01$ compared with jitai Tablet. compartment $\quad\left[\operatorname{High}: \mathrm{F}_{(1,18)}=5.59, \quad P<0.05 ; \quad \operatorname{Mid}: \mathrm{F}_{(1,18)}\right.$ $=23.76, P<0.01]$.

\section{Discussion}

Various animal behavior paradigms have been used to study neuronal substrates related to addiction, especially euphoria and reward, including self-stimulation, self-administration, and conditional position preference models. ${ }^{2}$

There are three general experimental models for evaluating physical dependence on opioids, including the spontaneous withdrawal test, precipitated withdrawal test and substitution test. ${ }^{31,36}$

The spontaneous withdrawal experiment refers to the administration of experimental animals (large, mouse and monkey) for a continuous period of time. The morphine is gradually increased to a certain dose and stabilized for a period of time. When the administration is suddenly interrupted, withdrawal signs are then observed. ${ }^{37}$ In the precipitated withdrawal experiment, the morphine is administered to the animal in a larger dose and multiple increments in a short period of time, and then an opioid antagonist such as naloxone is given to urge the animal to precipitate a withdrawal response. The onset of symptoms in precipitated withdrawal test is rapid, severe and typical, and the duration is short, which is convenient for observation and comparison. ${ }^{31}$ Mice often die due to the long cycle of morphine injection, so the injection method is generally used in rats to form a spontaneous withdrawal dependence model of opioids such as morphine. However, the precipitated withdrawal model can be achieved by injecting morphine into rats or mice. ${ }^{30,36}$

Weight loss in the rat spontaneous withdrawal model is widely selected as an evaluation indicator of physical dependence, which is relatively objective and quantitatively accurate. Other comprehensive scoring indicators were supplemented for evaluation. ${ }^{36}$ In the precipitated withdrawal test, the jumping reaction and weight loss of mice are the most objective, which is convenient for quantitative observation and statistical processing, so both of them are usually selected as the index of withdrawal symptoms. In addition to choosing the objective indicator of weight loss, agitation is a specific indicator of the rat's withdrawal response, so the modified Yanagi Koji score standard was also selected for comprehensive score comparison. ${ }^{29,30}$

The OA dose range in our study was estimated based on the relative composition of OA in organic extracts. This was compared to literature doses resulting in sedation, analgesia, and anti-inflammatory activities in mice. ${ }^{38-40}$ 
We studied the pharmacological effects of OA in four morphine-induced animal models, 2 in rats and 2 in mice. Firstly, we evaluated the improvement of withdrawal symptoms of OA after long-term morphine administration in rats. The results showed that on the 1, 3, and 5 days after taking OA, the spontaneous withdrawal symptoms were improved including the reduction of diarrhea and salivation, and the significant increase in body weight.

Then, we administered OA while giving morphine acutely to induce addiction in rats, and observed the effect of OA on improving the signs of naloxone-precipitated withdrawal. The results showed that the withdrawal scores of rats after taking OA decreased, indicating that OA may be able to combat morphine addiction. Thereafter, we repeated the administration of OA while morphine induced addiction acutely in mice, and obtained consistent experimental results which included reductions in the number of jumping reactions and weight increases in mice. This is because administration of the $\mu$-opioid receptor antagonist naloxone (in the absence of exogenous opioids) leads to a dramatic increase in firing frequency of these neurons. ${ }^{41}$ Moreover, chronic morphine exposure potentiates such naloxone-precipitated excitation. ${ }^{42}$

The CPP model is also a classic model for judging the improvement of animal addiction and withdrawal symptoms. $^{34,35,43}$ Therefore, we further investigated the effect of OA using the CPP model in morphine-induced mouse. Accordingly, results showed that OA significantly reduced the residence time of mice in the white box at different doses, suggesting that $\mathrm{OA}$ can significantly reduce the dependence of mice to morphine.

Although the nerve nuclei and neural pathways related to drug addiction and relapse in the CNS are very complex, the midbrain cortex DA system is the most closely related regulatory pathway related to addiction and relapse. ${ }^{44}$ The core brain area of this pathway includes the midbrain ventral tegmental area where the dopaminergic neuron inclusions are located and its dopaminergic nerve fibers innervate the brain area-PFC, NAc and other key structures. ${ }^{45,46}$

In addition to severe neurological and physical symptoms, the withdrawal syndrome associated with opiate dependence also involves important subjective reactions, including anxiety, anhedonia, depression, and drug cravings. ${ }^{47}$ After the physical symptoms of opioid withdrawal have disappeared, controlling and eliminating the longstanding subjective symptoms has been the main obstacle to the successful treatment of opioid dependence. ${ }^{48}$
Drug addiction involves various systems throughout the body, including DA, 5-HT, NE, acetylcholine, and histamine. ${ }^{13}$ Drug abuse is attributed to the excessive activation of the midbrain limbic DA system, which stimulates 5-HT and DA neurons. This system plays a vital role in mediating the active enhancement of opioids. ${ }^{49}$ Glutamatergic projections from the PFC and amygdala to the midbrain limbic reward pathway play a role in regulating DA neurons. ${ }^{50}$ When one becomes dependent on drugs, the synthesis of endogenous opioid peptides decreases and degradation increases. ${ }^{51}$ When in the withdrawal state, the activity and discharge of the central locus coeruleus (LC) and other parts of the blue nucleus increase, thereby promoting the synthesis and release of NE, DA and 5-HT, leading to acute withdrawal symptoms in the body. ${ }^{52}$

The latest research shows that orexinergic neurons innervate various brain structures, among which LC and lateral paragiant cell (LPGi) nuclei are recognized as two key mediators of opiate dependence and tolerance. OrexinA and -B neuropeptides are only synthesized in hypothalamic neurons. ${ }^{53}$ Many studies support that the orexin system is involved in mediating the effects of opioids by affecting the OX1Rs in LC and LPGi. There is an ample of evidence suggesting that withdrawal-induced hyperactivity of LC neurons plays a remarkable role in the expression of opioid withdrawal symptoms. ${ }^{54}$

Further reports have shown that orexin neurons are inhibited by 5 -HT neurons, primarily via 5 -HT, in both direct and indirect manners. ${ }^{55}$ Moreover, it has been shown that both Orexin-A and Orexin-B can inhibit the hypothalamic release of 5-HT, suggested that the feeding stimulating effects of the orexins could be mediated in part by an acute reduction of the anorectic serotonergic inputs to the hypothalamus. ${ }^{56}$

In this study, we used the double antibody sandwich method to determine the contents of 5-HT, DA, NE and serotonin in the serum or brain tissue of rats and mice. We found that while significantly reducing the spontaneous withdrawal symptoms of morphine-dependent rats, the serum 5-HT and DA levels also decreased to varying degrees. OA can significantly reduce the levels of NE and 5-HT in the PFC of rats with acute morphine addiction, and increase the content of endorphins. OA also significantly reduced the serum DA levels in mice, which is consistent with the results of previous rat withdrawal experiments. 
As mentioned above, when in a withdrawal state, the activity and discharge of neurons in the center of the LC and other parts of the blue nucleus increase, thereby promoting the synthesis and release of NE, DA and 5-HT which leading to acute withdrawal symptoms. After taking $\mathrm{OA}$, the synthesis and release of NE, DA, 5-HT are reduced, which promoted a significant improvement in withdrawal symptoms. Furthermore, the negative feedback of 5-HT affects the stimulating effect of orexin and reduces the discharge activity of LC, which may be a mechanism central to improving withdrawal symptoms.

There is also evidence that NMDA antagonists such as AP-5, MK-801 and memantine can prevent the acquisition of morphine-induced CPP and sensitivity to the beneficial effects of morphine. ${ }^{57,58} \mathrm{OA}$ attenuates the schizophrenialike behaviors induced by MK-801 in mice, indicating that it may play a role in the treatment of drug addiction although further verification is needed. ${ }^{59}$

Altogether, our findings showed that OA has various effects related to alleviating withdrawal symptoms, improving neurotransmitter levels, and reducing weight loss. This suggests OA may eventually play a role in the clinical treatment of drug addiction. However, although OA exhibits beneficial therapeutic effects on detoxification syndrome, the mechanisms involved clearly need further study. For instance, we have not reported classical doseresponse relationships in all 4 models when assessing study endpoints, and for certain assays only single doses were effective. Furthermore, we cannot exclude possible side effects related to drug-drug interactions.

\section{Conclusion}

Our study established that OA can improve the withdrawal symptoms of rats and mice, reduce the residence time of mice in the white box at different doses, and reduce the synthesis and release of NE, DA, and 5-HT, suggesting that OA may be useful in treatment of morphine addiction.

\section{Data Sharing Statement}

All data generated or analyzed during this study are included in this article. Further enquiries can be directed to the corresponding author.

\section{Ethics Approval and Consent to Participate}

The study was carried out in compliance with the ARRIVE guidelines. The animal protocol was reviewed and approved by the Ethical Committee Acts of Guangdong Provincial Institute of Traditional Chinese Medicine (No. SYXK2020-0059). All methods were carried out in accordance with the Guangdong Province Laboratory Animal Care and Use Guidelines.

\section{Acknowledgments}

The authors would like to express their gratitude to EditSprings for the expert linguistic services provided.

\section{Author Contributions}

All authors contributed to data analysis, drafting or revising the article, have agreed on the journal to which the article will be submitted, gave final approval of the version to be published, and agree to be accountable for all aspects of the work.

\section{Funding}

This project was supported by the Natural Science Foundation from education department of Jiangsu Province, China (Grant Number: 19KJB360001) and Changzhou Science and Technology and Information Bureau (Grant Number: CJ20189003 and CJ20190011).

\section{Disclosure}

The authors have no conflicts of interest to declare.

\section{References}

1. Lin L, Xi W. Drug addiction in China. Ann N Y Acad Sci. 2008;1141:304-317. doi:10.1196/annals.1441.025

2. Cami J, Farre M. Drug addiction. N Engl J Med. 2003;349 (10):975-986. doi:10.1056/NEJMra023160

3. Goldstein RZ, Volkow ND. Drug addiction and its underlying neurobiological basis: neuroimaging evidence for the involvement of the frontal cortex. Am J Psychiatry. 2002;159(10):1642-1652. doi:10.1176/appi.ajp.159.10.1642

4. Alvarez V, Arttamangkul S, Williams JT. A RAVE about opioid withdrawal. Neuron. 2001;32(5):761-763. doi:10.1016/S08966273(01)00530-X

5. Gonzalez G, Oliveto A, Kosten TR. Treatment of heroin (diamorphine) addiction: current approaches and future prospects. Drugs. 2002;62(9):1331-1343. doi:10.2165/00003495-200262090-00004

6. Kreek MJ, LaForge KS, Butelman E. Pharmacotherapy of addictions. Nat Rev Drug Discov. 2002;1(9):710-726. doi:10.1038/nrd897

7. David H. Prescription drug addiction: the treatment challenge. Lancet. 2012;379(9810):17-18. doi:10.1016/S0140-6736(12)60007-5

8. Gardner EL. Addiction and brain reward and antireward pathways. AdvPsychosom Med. 2011;30:22-60. doi:10.1159/000324065

9. Volkow ND, Fowler JS, Wang GJ. The addicted human brain: insights from imaging studies. $J$ Clin Invest. 2003;111 (10):1444-1451. doi:10.1172/JCI18533

10. Volkow ND, Li TK. Drugs and alcohol: treating and preventing abuse, addiction and their medical consequences. PharmacolTher. 2005;108(1):3-17. 
11. Horseman C, Meyer A. Neurobiology of Addiction. ClinObstet Gynecol. 2019;62(1):118-127. doi:10.1097/GRF.0000000000000416

12. Aguilar MA, Manzanedo C, Do Couto BR, Rodriguez-Arias M, Minarro J. Memantine blocks sensitization to the rewarding effects of morphine. Brain Res. 2009;1288:95-104. doi:10.1016/j. brainres.2009.06.100

13. Nestler EJ, Aghajanian GK. Molecular and cellular basis of addiction. Science. 1997;278(5335):58-63. doi:10.1126/science.278. 5335.58

14. Zhu YP, Long ZH, Zheng ML, Binsack R. Effect of glycine site/ NMDA receptor antagonist MRZ2/576 on the conditioned place preference and locomotor activity induced by morphine in mice. J Zhejiang UnivSci B. 2006;7(12):998-1005. doi:10.1631/jzus.2006. B0998

15. Huang JB, Yang QH, Chen YX, et al. Detoxification-used traditional Chinese medicine composition and preparation method thereof National Intellectual Property Administration of China; 2013. Available from: http://pss-system.cnipa.gov.cn/sipopublicsearch/patent search/showViewList-jumpToView.shtml. Accessed August 11, 2021.

16. Liu J. Pharmacology of oleanolic acid and ursolic acid. $J$ Ethnopharmacol. 1995;49(2):57-68. doi:10.1016/0378-8741(95) 90032-2

17. Liu J. Oleanolic acid and ursolic acid: research perspectives. J Ethnopharmacol. 2005;100(1-2):92-94. doi:10.1016/j.jep.2005.05.024

18. Dzubak P, Hajduch M, Vydra D, et al. Pharmacological activities of natural triterpenoids and their therapeutic implications. Nat Prod Rep. 2006;23(3):394-411. doi:10.1039/b515312n

19. Pollier J, Goossens A. Oleanolic acid. Phytochemistry. 2012;77:10-15. doi:10.1016/j.phytochem.2011.12.022

20. Somova L, Shode FO, Ramnanan P, Nadar A. Antihypertensive, antiatherosclerotic and antioxidant activity of triterpenoids isolated from Olea europaea, subspecies africana leaves. J Ethnopharmacol. 2003;84(2-3):299-305. doi:10.1016/S0378-8741(02)00332-X

21. Gui B, Hua F, Chen J, Xu Z, Sun H, Qian Y. Protective effects of pretreatment with oleanolic acid in rats in the acute phase of hepatic ischemiareperfusion injury: role of the PI3K/Akt pathway. Mediators Inflamm. 2014;2014:451826. doi:10.1155/2014/451826

22. Litao Y, Jing L, Qing L, et al. Antidepressant-like effect of oleanolic acid in rats exposed to the repeated forced swimming test. $J$ Psychopharm. 2013;27(5):459-468. doi:10.1177/0269881112467090

23. Liu Y, Han M, Liu X, et al. Dopamine transporter availability in heroin-dependent subjects and controls: longitudinal changes during abstinence and the effects of Jitai tablets treatment. Psychopharmacology. 2013;230(2):235-244. doi:10.1007/s00213013-3148-z

24. Liu J, Gao JL, Tu SA, et al. Neuroprotective Effects of Jitai Tablet, a Traditional Chinese Medicine, on the MPTP-Induced Acute Model of Parkinson's Disease: involvement of the Dopamine System. Evid Based Complement Alternat Med. 2014;2014:542383. doi:10.1155/ 2014/542383

25. Fan HY, Sun L, Li XX, et al. Effects of Jitai tablet, a traditional Chinese medicine, on plasma adrenocorticotropic hormone and cortisol levels in heroin addicts during abstinence. J Altern Complement Med. 2014;20(7):527-534. doi:10.1089/acm.2012.0804

26. $\mathrm{Xu} \mathrm{SS}, \mathrm{Tu} \mathrm{SA}, \mathrm{Gao} J$, et al. Protective and restorative effects of the traditional Chinese medicine Jitai tablet against methamphetamine-induced dopaminergic neurotoxicity. BMC Complement Altern Med. 2018;18(1):76. doi:10.1186/s12906-018-2094-z

27. Lefevre EM, Pisansky MT, Toddes C, et al. Interruption of continuous opioid exposure exacerbates drug-evoked adaptations in the mesolimbic dopamine system. Neuropsychopharmacology. 2020;45 (11):1781-1792. doi:10.1038/s41386-020-0643-x

28. Wen D, Zhao P, Hui R, et al. Hydrogen-rich saline attenuates anxiety-like behaviors in morphine-withdrawn mice. Neuropharmacology. 2017;118:199-208. doi:10.1016/j.neuropharm.2017.03.029
29. Kourosh-Arami M, Joghataei MT, Komaki A, Gholami M, Najafi Z, Lavaie M. Persistent effects of the orexin-1 receptor antagonist SB-334867 on naloxone precipitated morphine withdrawal symptoms and nociceptive behaviors in morphine dependent rats. Int J Neurosci. 2020;11:1-10. doi:10.1080/00207454.2020.1802266

30. Harvey-Lewis C, Brisebois AD, Yong H, Franklin KB. Naloxoneprecipitated withdrawal causes an increase in impulsivity in morphine-dependent rats. BehavPharmacol. 2015;26(3):326-329. doi:10.1097/FBP.0000000000000106

31. Zhang Q. Research Methodology of Chinese Medicine Pharmacology. Beijing, China: People's Medical Press; 1993:909-910.

32. Kasanga EA, Boakye-Gyasi E, Biney RP, Kyekyeku JO, Agyare C, Woode E. Geraniin attenuates naloxone-precipitated morphine withdrawal and morphine-induced tolerance in mice. $J$ Intercult Ethnopharmacol. 2017;6(2):199-205. doi:10.5455/ jice.20161229015413

33. Pedrón VT, Varani AP, Balerio GN. Baclofen prevents the elevated plus maze behavior and BDNF expression during naloxone precipitated morphine withdrawal in male and female mice. Synapse. 2016;70(5):187-197. doi:10.1002/syn.21886

34. Mohsen I, Reza Q, Mahmoud H, Hossein H. Inhibitory Effect of Berberis vulgaris Aqueous Extract on Acquisition and Reinstatement Effects of Morphine in Conditioned Place Preferences (CPP) in Mice. Jundishapur J Nat Pharm Prod. 2014;9(3):e16145. doi:10.17795/ jjnpp-16145

35. VahdatiHassani F, Hashemzaei M, Akbari E, Imenshahidi M, Hosseinzadeh $\mathrm{H}$. Effects of berberine on acquisition and reinstatement of morphine-induced conditioned place preference in rats. Avicenna J Phytomed. 2016;6(2):198-204.

36. Zhang KG. Animal experimental methods for drug dependence. Chine J Drug Dependence. 1999;8(1):23-26.

37. Allahverdiyev O, Türkmen AZ, Nurten A, Sehirli I, Enginar N. Spontaneous withdrawal in intermittent morphine administration in rats and mice: effect of clonidine coadministration and sex-related differences. Turk J Med Sci. 2015;45(6):1380-1389. doi:10.3906/sag1408-137

38. Vasconcelos MA, Royo VA, Ferreira DS, Crotti AE. In vivo analgesic and anti-inflammatory activities of ursolic acid and oleanoic acid from Miconiaalbicans (Melastomataceae). Z Naturforsch C $J$ Biosci. 2006;61(7-8):477-482. doi:10.1515/znc-2006-7-803

39. Park SJ, Lee Y, Oh HK, et al. Oleanolic acid attenuates MK-801induced schizophrenia-like behaviors in mice. Neuropharmacology. 2014;86:49-56. doi:10.1016/j.neuropharm.2014.06.025

40. Fajemiroye JO, Galdino PM, Florentino IF, et al. Plurality of anxiety and depression alteration mechanism by oleanolic acid. $J$ Psychopharmacol. 2014;28(10):923-934. doi:10.1177/0269881114536789

41. Li Y, van den Pol AN. Mu-opioid receptor-mediated depression of the hypothalamic hypocretin/orexin arousal system. J Neurosci. 2008;28(11):2814-2819. doi:10.1523/JNEUROSCI.5447-07.2008

42. Thomaz AC, Iyer V, Woodward TJ, Hohmann AG. Fecal microbiota transplantation and antibiotic treatment attenuate naloxone-precipitated opioid withdrawal in morphine-dependent mice. Exp Neurol. 2021;343:113787. doi:10.1016/j.expneurol.2021.113787

43. Morón JA, Gullapalli S, Taylor C, Gupta A. Modulation of opiate related signaling molecules in morphine-dependent conditioned behavior: conditioned place preference to morphine induces CREB phosphorylation. Neuropsychopharmacology. 2010;35(4):955-966. doi:10.1038/npp.2009.199

44. Farrell MR, Schoch H, Mahler SV. Modeling cocaine relapse in rodents: behavioral considerations and circuit mechanisms. Prog Neuropsycho Pharmaco lBiol Psychiatry. 2018;87(Pt A):33-47. doi:10.1016/j.pnpbp.2018.01.002

45. Juarez B, Han MH. Diversity of Dopaminergic Neural Circuits in Response to Drug Exposure. Neuropsychopharmacology. 2016;41 (10):2424-2446. doi:10.1038/npp.2016.32 
46. Ranaldi R. Dopamine and reward seeking: the role of ventral tegmental area. Rev Neurosci. 2014;25(5):621-630. doi:10.1515/ revneuro-2014-0019

47. Kalivas PW, Volkow ND. The neural basis of addiction: a pathology of motivation and choice. Am J Psychiatry. 2005;162(8):1403-1413. doi:10.1176/appi.ajp.162.8.1403

48. Childress AR, Ehrman R, McLellan AT, MacRae J, Natale M, O'Brien CP. Can induced moods trigger drug-related responses in opiate abuse patients? J Subst Abuse Treat. 1994;11(1):17-23. doi:10.1016/0740-5472(94)90060-4

49. Murphy SM, McCollister KE, Leff JA, et al. Cost-Effectiveness of Buprenorphine-Naloxone Versus Extended-Release Naltrexone to Prevent Opioid Relapse. Ann Intern Med. 2019;170(2):90-98. doi:10.7326/M18-0227

50. Xing B, Li YC, Gao WJ. Norepinephrine versus dopamine and their interaction in modulating synaptic function in the prefrontal cortex. Brain Res. 2016;1641(Pt B):217-233. doi:10.1016/j.brainres.20 16.01 .005

51. Chen W, Nong Z, Li Y, Huang J, Chen C, Huang L. Role of Dopamine Signaling in Drug Addiction. Curr Top Med Chem. 2017;17(21):2440-2455. doi:10.2174/1568026617666170504100642

52. Solinas M, Belujon P, Fernagut PO, Jaber M, Thiriet N. Dopamine and addiction: what have we learned from 40 years of research. J Neural Transm. 2019;126(4):481-516. doi:10.1007/s00702-0181957-2

53. Ahmadi-Soleimani SM, Ghaemi-Jandabi M, Azizi H, Semnanian S. Orexin type 1 receptor antagonism in Lateral Paragigantocellularis nucleus attenuates naloxone precipitated morphine withdrawal symptoms in rats. Neurosci Lett. 2014;558:62-66. doi:10.1016/j. neulet.2013.10.064
54. Harris GC, Aston-Jones G. Augmented accumbal serotonin levels decrease the preference for a morphine associated environment during withdrawal. Neuropsychopharmacology. 2001;24(1):75-85. doi:10.1016/S0893-133X(00)00184-6

55. Ahmadi-Soleimani SM, Azizi H, Gompf HS, Semnanian S. Role of orexin type-1 receptors in paragiganto-coerulear modulation of opioid withdrawal and tolerance: a site specific focus. Neuropharmacology. 2017;126:25-37. doi:10.1016/j.neuropharm.2017.08.024

56. Ghaemi-Jandabi M, Azizi H, Ahmadi-Soleimani SM, Semnanian S. Intracoerulear microinjection of orexin-A induces morphine withdrawal-like signs in rats. Brain Res Bull. 2017;130:107-111. doi:10.1016/j.brainresbull.2017.01.010

57. Harris GC, Wimmer M, Byrne R, Aston-Jones G. Glutamateassociated plasticity in the ventral tegmental area is necessary for conditioning environmental stimuli with morphine. Neuroscience. 2004;129(3):841-847. doi:10.1016/j.neuroscience.2004.09.018

58. Park SH, Sim YB, Kang YJ, et al. Mechanisms involved in the antinociceptive effects of orally administered oleanolic acid in the mouse. Arch Pharm Res. 2013;36(7):905-911. doi:10.1007/s12272-013-0093-7

59. Yunmin L, Meiying Z, Wei C, et al. Oleanolic acid induces apoptosis of MKN28 cells via AKT and JNKsignaling pathways. Pharm Biol. 2014;52(6):789-795. doi:10.3109/13880209.2013.864683

\section{Publish your work in this journal}

Drug Design, Development and Therapy is an international, peerreviewed open-access journal that spans the spectrum of drug design and development through to clinical applications. Clinical outcomes, patient safety, and programs for the development and effective, safe, and sustained use of medicines are a feature of the journal, which has also been accepted for indexing on PubMed Central. The manuscript management system is completely online and includes a very quick and fair peer-review system, which is all easy to use. Visit http://www. dovepress.com/testimonials.php to read real quotes from published authors. 